\title{
PRODUTOS E SERVIÇOS INFORMACIONAIS EM ARQUIVOS PÚBLICOS: PANORAMA DOS ARQUIVOS DAS SECRETARIAS DO ESTADO DA PARAÍBA
}

\author{
Kessia Karla Portela Richene Silva \\ Bacharel em Arquivologia \\ kessiakarlaa@gmail.com \\ Sonia Luiza Freitas dos Santos \\ Bacharel em Arquivologia \\ soninhajp35@gmail.com \\ Jefferson Peres da Silva \\ Bacharelando em Arquivologia \\ jefferson.cdmd@gmail.com \\ Ana Claudia Cruz Córdula \\ Professora do Departamento de Ciência da Informação - UFPB \\ Doutoranda em Ciência da Informação PPGCI/UFPB \\ anacordula@gmail.com
}

Resumo

\begin{abstract}
Aborda a disponibilidade da oferta de produtos e serviços nos arquivos públicos da Paraíba. Trata-se de uma pesquisa descritiva com abordagem quantitativa e qualitativa. Utilizou-se como instrumento para a coleta de dados o questionário, aplicado a uma amostra de seis secretarias pesquisadas. Com o objetivo de conhecer a oferta de produtos e serviços informacionais nos arquivos públicos do Estado da Paraíba no ambiente tradicional e virtual. Apresenta os aspectos conceituais, tipológicos e definições de serviços e produtos informacionais arquivísticos. Mostra o papel do arquivista como profissional da informação, bem como suas habilidades e competências para promover a divulgação dos produtos e serviços nas organizações. A pesquisa revela limitações dos profissionais nos arquivos públicos da Paraíba impossibilitando as potencialidades informacionais. Conclui-se que existe uma baixa oferta de produtos e serviços nos arquivos das secretarias, principalmente no ciberespaço devido à ausência de disponibilidade de recursos humanos e financeiros para implementá-los.
\end{abstract}

Palavras-chave: Arquivos Públicos - Paraíba. Arquivos Públicos - Produtos e Serviços

\section{INTRODUÇÃO}

Devido à necessidade de organizar os conteúdos informacionais que permeiam seus acervos e de disseminar essas informações, a Arquivologia passou a atuar em ação interdisciplinar, especialmente com a Ciência da Informação, a Computação e a Biblioteconomia, visando identificar, principalmente, a possibilidade de criar produtos e serviços especializados que possam ser úteis para a prática arquivística.
Este estudo debruça-se sobre a percepção das práticas arquivísticas a respeito da oferta de produtos e serviços informacionais arquivísticos, nos arquivos públicos das Secretarias do Estado da Paraíba e de como esses produtos e serviços contribuem para a organização e a disseminação dos acervos, embora muitas instituições públicas, em todas as esferas do governo, ainda não percebam a importância de sua aplicabilidade para 
melhorar a organização da informação e o acesso a ela rápido e eficaz.

Como fonte de informação, o arquivo é uma ponte que leva o usuário ao acesso à informação, independentemente do suporte em que ela se materializa. Nesse contexto, compreendendo a informação como uma ferramenta que determina o desempenho das várias atividades e ações cotidianas de um indivíduo ou de uma instituição e que sua produção é feita de maneira natural e orgânica, entendemos que o seu acesso e seu uso são necessários para o desempenho eficaz dessas atividades.

$\mathrm{Na}$ atual sociedade da informação (CASTELLS, 2003), marcada pelo uso das tecnologias de informação e comunicação e pelo rápido acesso às informações, percebemos que a informação toma o posto de instrumento importante na perspectiva estratégica para o desenvolvimento, impulsionando as relações sociais, culturais, profissionais e intelectuais. Nesse contexto, a informação orgânica, objeto maior das práticas arquivísticas, como instrumento de transformação, precisa ser disseminada para ser acessada mais rapidamente pelo usuário. Diante desse cenário, recai sobre os arquivos a importância de que as informações sejam cada vez mais democráticas e acessíveis (MARTELETO, 1992).

No contexto dos arquivos públicos, o acesso à informação é peça fundamental, porque esses arquivos têm a finalidade de servir à administração pública em todos os âmbitos e assumem um papel importante na sociedade, especialmente com a implementação da Lei de Acesso à Informação ${ }^{1}$. Seus focos se voltam para garantir a acessibilidade, a guarda, a preservação, o sigilo e a integridade dos documentos um arquivo público. Em sua fase permanente, um arquivo público detém documentos de valor legal e histórico para a sociedade, deixa de servir de apoio à administração, assume um papel social e memorialístico, o que reforça seu potencial informativo e histórico, e possibilita a realização de pesquisas científicas.

Tendo em vista a escassez de pesquisas realizadas que tratam sobre produtos e serviços

\footnotetext{
${ }^{1}$ Lei $\mathrm{n}^{\mathrm{o}} 12.527$, de 18 de novembro de 2011, que dispõe sobre o acesso à informação, o que representa um dos grandes avanços proporcionados
}

de informação no panorama dos arquivos, este artigo foi produzido com o intuito de contribuir para o cenário científico da Arquivologia e sua relação com os produtos e os serviços de informação. O campo da pesquisa envolveu os arquivos das Secretarias Estaduais do estado da Paraíba, com o objetivo de traçar um panorama da existência dos produtos e dos serviços de informação nos referidos arquivos.

Algumas problemáticas assolam a realidade nos arquivos públicos, entre as quais, destacamos: a falta de estrutura e de recursos materiais e financeiros, de recursos humanos, de equipamentos, de espaço e de profissionais capacitados em arquivologia, refletindo em dificuldades na área de tratamento técnico dos documentos e a falta de instrumentos de pesquisa e gestão de documentos, que dificultam severamente o acesso à informação nas instituições.

Nessa perspectiva, este estudo tem os seguintes objetivos: conhecer a oferta de produtos e serviços nos arquivos públicos das Secretarias do Estado da Paraíba no ambiente tradicional e virtual e identificar os mais utilizados nesses arquivos; analisar as habilidades e as competências dos arquivistas ou dos responsáveis pelo arquivo, para o desenvolvimento de produtos e serviços nesses arquivos estaduais, e levantar as dificuldades de implementar os produtos e os serviços informacionais arquivísticos.

\section{NAS VEREDAS DA TEORIA}

A evolução tecnológica alcança as múltiplas áreas do conhecimento, inclusive no contexto dos arquivos e, ao se encontrar com a tecnologia, potencializa suas práticas, facilitando desde a gestão documental, até a possibilidade de criar instrumentos de pesquisa on line, de produtos e serviços que viabilizem o tratamento, o acesso, o uso e a disseminação das informações arquivísticas.

A Arquivologia é uma ciência que apresenta uma relação interdisciplinar com a tecnologia e com outras áreas do conhecimento e agrega ao cenário dos arquivos mais potenciais, especialmente com o foco na disseminação, no acesso e no uso das informações que abrigam. Nesse contexto, especialmente no marketing e na computação,

pela elucidação dieta de um capítulo até então obscuro da história recente do Brasil. 
destacamos as relações mais estreitas com a arquivologia, quando tratamos sobre a possibilidade de ofertarmos produtos $\mathrm{e}$ serviços informacionais, acrescentando um diferencial aos arquivos, além de possibilitar o alcance mais facilmente de novos usuários, atraídos pela inovação dos produtos e serviços que se implementam. A seguir, transitaremos nas veredas teóricas do arquivo, dos produtos e dos serviços de informação, com o fim de investigar como essa relação acontece e de entender o papel do profissional arquivista no percurso de implantação prática dos produtos e serviços da informação arquivística.

\subsection{ARQUIVO: ASPECTOS HISTÓRICOS E CONCEITUAIS}

As primeiras manifestações de espaços específicos voltados para a guarda e a preservação de acervos documentais nos remetem à invenção da escrita e ao estabelecimento das primeiras cidades há mais de cinco milênios (ARAÚJO, 2011).

No contexto do surgimento dos arquivos, não podemos deixar de mencionar $o$ surgimento da escrita, que ocorreu nas civilizações do Médio Oriente, há cerca de seis mil anos (CHAGAS; PEREIRA, 2011). No cenário europeu, foi a partir da Idade Média que se organizaram os grandes arquivos, embora, nesse período, ainda não houvesse uma estrutura única, direcionada apenas às atividades arquivísticas, e o espaço físico comum aos arquivos eram as bibliotecas e os museus. Com o decorrer dos anos, foi necessário aperfeiçoar as técnicas de organização específicas dos arquivos e desmembrar a questão física, alocando-se espaços específicos para o desenvolvimento das unidades de informações específicas, isto é, arquivos, bibliotecas e museus.

Falar sobre arquivo nos remete a algumas acepções. Ele pode ser considerado como instituição, cuja finalidade é de manter os documentos sob sua custódia ou no espaço de armazenamento. Podemos também associá-lo ao mobiliário, um móvel onde guardamos a documentação, ou um conjunto documental (SILVA, 2011).

Para Lopes (2009 p.40), “[...] arquivos são documentos produzidos ou recebidos por pessoa física ou jurídica, decorrentes do desenvolvimento de suas atividades, sejam elas de caráter administrativo, técnico, artísticos ou científico, independente da sua idade e valores intrínsecos". O referido autor relata um conceito que se aproxima do que dispõe a Lei $8.159 / 91$, que trata da política nacional de arquivos públicos e privados e dá outras providências e em cujo artigo $2^{\circ}$ discorre:

Consideram-se arquivos, para os fins dessa Lei, os conjuntos de documentos produzidos e recebidos por órgãos públicos, instituições de caráter público e entidades privadas, em decorrência do exercício de atividades específicas, bem como por pessoa física, qualquer que seja o suporte da informação ou a natureza dos documentos (BRASIL, 1991).

Diante desse contexto, consideramos arquivo, no percurso desta pesquisa, o conjunto de documentos que carregam informações que, para serem acessadas, precisam ser organizadas, tratadas e disseminadas.

Quanto à finalidade dos arquivos, a principal delas é de servir à administração, porém com o decorrer do tempo, passa a ser base do conhecimento histórico e científico (PAES, 2006). Os arquivos são partes integrantes da sociedade da informação e portadores de conteúdos informacionais importantes para a sociedade.

No que diz respeito à classificação dos arquivos, recorremos às perspectivas teóricas de Paes (2006) e de Bellotto (2006). O primeiro classifica os arquivos de acordo com quatro categorias: quanto às entidades mantenedoras: os arquivos podem ser públicos ou privados (grifo nosso); quanto à extensão de sua atuação: setoriais ou e centrais (grifo nosso); quanto à natureza dos documentos: especiais ou especializados (grifo nosso); e quanto aos estágios de sua evolução: correntes, intermediários e permanentes (grifo nosso). Já Bellotto (2006) classifica os arquivos como públicos e privados. A autora afirma que não existem mais do que duas categorias de arquivos, por isso eles são classificados em públicos e privados. É nessa perspectiva que nos ancoramos.

Os arquivos privados apresentam características próprias e dividem-se em: de pessoa jurídica ou de pessoa física. Os de pessoa jurídica englobam as instituições privadas com ou sem fins lucrativos, e os de pessoa física dizem respeito a uma única pessoa e podem também ser familiar (SILVA; 2011). Já os arquivos públicos, segundo 
Bellotto (2006), existem com a finalidade de recolher, custodiar, preservar e organizar fundos documentais originados na área governamental e servem à administração, ao cidadão, aos pesquisadores e à sociedade em geral. Para além das competências administrativas, "[...] cumpre-lhe, ainda, uma atividade que, embora secundária, é a que melhor pode desenhar os seus contornos sociais, dando-lhe projeção na comunidade, trazendo-lhe a necessária dimensão popular e cultural que reforça e mantém o seu objetivo primeiro" (BELLOTTO, 2006, p. 227).

Os arquivos públicos não estão vinculados somente ao valor primário, isto é, ao seu valor administrativo, mas também, sobretudo, ao valor secundário, histórico e memorialístico, portanto também é importante do ponto de vista social. Logo, os documentos produzidos e/ou recebidos nos arquivos públicos, independentemente de sua esfera, são identificados como correntes, intermediários e permanentes, e em cada uma dessas fases, é fundamental aplicar métodos e técnicas arquivísticas, para viabilizar o acesso e o uso da informação pública.

\subsection{PRODUTOS E SERVIÇOS INFORMACIONAIS: ASPECTOS CONCEITUAIS}

Considerando a relação dos produtos e dos serviços de informação, compreendemos que os produtos são tangíveis e se apresentam através de propriedades como formato, suporte, entre outros (BORGES; 2007). Silva (2013) corrobora essa assertiva por compreender o produto como um bem tangível, ou seja, materializado, visível, palpável, perecível e oferecido a fim de atender às necessidades ou aos desejos do usuário. Mas $\mathrm{o}$ autor alerta que, devido à velocidade com que a tecnologia avança, devemos ficar atentos para a possibilidade de o produto poder tornarse obsoleto, quando se inserir no contexto tecnológico.

Para além dessa compreensão, é possível ampliar o conceito de produtos com base no pensamento de Kotler e Keller (2006), que afirmam:

Muitas pessoas acham que um produto é uma oferta tangível, mas ele pode ser bem mais do que isso. Um produto é tudo o que pode ser oferecido a um mercado para satisfazer a necessidade de um desejo. Entre os produtos comercializados estão bens físicos, serviços, experiências, eventos, pessoas, lugares, propriedades, organizações, informações e ideias (KOTLER; KELLER, 2006, p. 366). (grifo nosso).

No que tange aos produtos e aos serviços de informação, os autores despertam para a linha tênue que existe entre eles. Logo a aplicação de um produto pode estar, paralelamente, promovendo um serviço. Assis (2006) considera que cada produto tem características específicas e objetivos distintos em relação ao atendimento ao usuário. Por isso os produtos de informação devem ser pensados visando alcançar os usuários e atingir sua necessidade informacional.

Quanto aos serviços, são conhecidos por sua intangibilidade, pois não podem ser vistos, provados, sentidos, ouvidos, isto é, materializados. Nesse caso, são considerados como ações ou atividades realizadas para atender às necessidades dos usuários, e sua execução pode estar ou não vinculada a um produto físico. Rozados (2004, p.25-27) afirma que os serviços de informação são

1) [...] todo processo de auxílio ao leitor na busca de informação ou na satisfação de suas necessidades informacionais [...]. 2) É a interface direta entre a informação e o usuário. [...] 3) Atividade destinada à identificação, aquisição, processamento e transmissão de informação e ao seu fornecimento em um serviço ou produto de informação[...].

A função de um serviço de informação é de assegurar que qualquer informação requerida esteja à disposição do usuário, em menos tempo possível, de preferência, no momento em que for solicitada (ROZADOS, 2004). Isso justifica a importância dos serviços de informação para viabilizar o encontro da informação com o usuário, pois, independentemente de ser interno ou externo, o serviço de informação possibilita a eficácia da unidade de informação.

O contato com o usuário é um fator importante durante a prestação de um serviço, para que ele consiga ter acesso às informações desejadas. Behr, Moro e Estabel (2010, p. 46) afirmam que "[...] é importante verificar que no momento em que o serviço é prestado em contato direto com o cliente, esse se torna algo muito particular e por isso deve atender 
pontualmente às necessidades de um sujeito em especial". Nesse contexto, conhecer o usuário e suas necessidades é um fator importante para prestarmos um serviço de informação de boa qualidade. Sobre essa perspectiva, Borges (2007, p. 119) acrescenta:

Compreender o comportamento do usuário do serviço ou produto de informação é essencial, pois mostra como e porque esse usuário escolhe e utiliza ou não determinado serviço ou produto de informação informacional possibilitando-se a avaliação e adequação do mesmo.

Em uma instituição arquivística, para entender a relação entre os produtos e os serviços de informação e os usuários, é preciso analisar se os usuários sabem de existência e como estão sendo utilizados para o alcance das informações. Avaliar sua utilização e eficácia no processo é crucial, para sabermos se, de fato, estão atingindo seu propósito, que é de alcançar o usuário, com o fim de suprir sua demanda informacional.

Avaliar os produtos e os serviços informacionais possibilita uma espécie de feedback, que pode ser realizado através da aplicação de instrumentos de avaliação, como entrevistas, questionários, formulários, entre outros. A partir dos resultados das avaliações, quando necessário, é importante adequá-los, para alcançar o propósito de sua criação e, consequentemente, atingir a satisfação informacional do usuário do arquivo. Para compreendermos bem essa relação, no tópico seguinte, apresentamos alguns produtos e serviços de informação arquivística.

\subsubsection{Produtos e serviços informacionais arquivísticos}

Os produtos e os serviços nos arquivos têm uma proporção diferenciada mercadologicamente do que acontece em outros contextos (SILVA, 2013). Para tornar os produtos e os serviços prontos para utilização, o arquivo tem que manter o acervo organizado, preservado, conservado, íntegro e acessível aos usuários. Logo, entendemos que os produtos informacionais arquivísticos são resultados tangíveis que permeiam o processo de gestão da informação (coleta, análise, tratamento, disseminação e armazenamento) e que, se bem elaborados, podem atingir com mais facilidade seu propósito, que é de disseminar a existência e a importância do arquivo e tornar mais acessíveis as informações imersas na documentação que ele comporta.

Partindo dessa perspectiva, é importante manter a informação organizada, segura, disponível e em ótimas condições para ser suprida sempre que forem solicitadas. Para reforçar essa concepção, Gonçalves, Gouveia e Petinari (2008, p. 46-47) asseguram:

Uma informação solta, não contextualizada, não é um produto. Para que seja reconhecida e compreendida como produto, primeiramente, precisa estar focada em determinada direção e objetivo. Então, depois de direcionada, a informação será um produto e poderá, como qualquer outro nas mesmas condições, alcançar o seu sentido natural, o motivo pelo qual existe, ou seja, aumentar o grau de certeza em uma tomada de decisão.

A oferta de produtos nos arquivos pode ser verificada em itens dos mais variados suportes em que a informação está registrada e ser disponibilizada tanto em meio tradicional, através de guias, inventários, catálogos, folders, panfletos etc., quanto no ciberespaço, por meio de sites, blogs, vídeos, catálogos on line, repositórios digitais, entre outros. $\mathrm{O}$ arquivo deve não só desenvolver produtos nos seus mais variados suportes como também conhecer as particularidades, os desejos, as percepções e as preferências dos usuários, além das expectativas desses usuários em relação aos produtos e aos serviços que o arquivo disponibiliza. A partir daí, melhorias, adequações e ajustes deverão ser feitos nessas unidades de informação, visando à satisfação e ao atendimento das demandas dos usuários.

De acordo com Albuquerque (2015), os serviços nos arquivos são voltados tanto para os produtos quanto para os usuários. A autora refere que os serviços dos arquivos voltados para os produtos são provenientes das atividades de protocolo, avaliação, seleção, organização, classificação higienização, restauração, preservação, digitalização, acondicionamento e cópia de exemplares. Já os serviços voltados para usuários são materializados por meio da disseminação da informação, do atendimento e da difusão educativa, cultural e editorial, da descrição documental e da elaboração de instrumentos de pesquisa. Esses são serviços que, geralmente, são rotineiros nos arquivos, mas 
são sobremaneira importes para manter a documentação e a informação em bom estado.

É imprescindível que o arquivo busque novas formas de promover os serviços dentro da organização, principalmente porque vivemos na era da informação, em que o usuário passa a ser um componente importante, quiçá, o mais importante no processo de organização, de acesso e de uso da informação arquivística. As práticas arquivísticas estão centradas em viabilizar o acesso e o uso da informação, e a tecnologia possibilita a formulação de produtos informacionais que viabilizem o serviço eficaz no contexto do arquivo. Logo, sites, blogues, fun pages, instrumentos de pesquisa digitais e vídeos institucionais são uma ponte entre o usuário e seu alcance à informação e facilitam a aplicação dos serviços informacionais.

A promoção de produtos e serviços na rede web pode agregar valor às demandas informacionais e proporcionar um atendimento diferenciado aos usuários que usam os recursos tecnológicos. Os serviços informacionais eletrônicos promovem melhorias tanto para usuários internos da organização quanto para os externos, por meio da disponibilização de softwares, serviços de referência por chat, mala direta eletrônica, visita virtual, entre outros.

Castro e Suaiden (2015) afirmam que as novas tecnologias da informação e comunicação impulsionam os profissionais da informação a reverem a forma de ofertar seus produtos e serviços dentro das organizações, a fim de atender às novas necessidades do usuário, com a possibilidade de avançar dos meios tradicionais para o contexto digital. Essas adaptações são necessárias, pois os usuários estão sempre se adequando às transformações sociais e aos avanços tecnológicos e fazem parte dessas transformações. Interagir com os produtos e os serviços no contexto digital possibilita ao arquivo ampliar e diversificar sua oferta de produtos e serviços, além de alcançar mais facilmente os usuários, quebrando as barreiras físicas e geográficas.

No contexto dos arquivos públicos, observamos que os produtos e os serviços são mais utilizados pelos usuários internos da instituição e que a maioria deles está voltada para o uso e a busca do suporte tradicional, tendo em vista que a escassez de recursos culmina, muitas vezes, em investimentos reduzidos no contexto tecnológico. Independentemente do suporte em que a informação arquivística se materializa, os arquivos têm a finalidade de disponibilizar informações que estão sob sua guarda, de preferência, com rapidez e segurança, com o fim de satisfazer às necessidades informacionais de seus usuários.

Partindo dessa concepção,

[...] é necessário atrair, conquistar e fidelizar os usuários através da boa prestação de produtos e serviços de qualidade, principalmente se tratando de arquivos públicos, ou até mesmo dos arquivos pessoais e privados abertos ao público, que também resguardam informações de interesse da sociedade. (ALBUQUERQUE, 2015. p. 6).

$\mathrm{Na}$ prática da gestão documental dos arquivos, destacamos a importância dos produtos e dos serviços para o êxito desse processo na instituição. Sobre isso, Albuquerque (2015, p.6) afirma que

[...] a maioria das instituições não realizam todos os procedimentos ou até mesmo nenhum que engloba a gestão da documentação/informação, sendo essa uma atividade de grande relevância para se obter um arquivo organizado e preparado para dispor de bons produtos e serviços.

A tabela de temporalidade e o plano de classificação são procedimentos relacionados à gestão documental/informacional, a priori, um dos produtos mais efetivos dentro desses arquivos, por meio dos quais é possível identificar os documentos, determinar seu prazo de permanência e destinação final ou eliminar com segurança, de acordo com os procedimentos técnicos e legais, os documentos desprovidos de valor, sem que haja prejuízo para a organização ou para a sociedade.

Podemos perceber que, mesmo imersos nos avanços tecnológicos e na conscientização dos profissionais sobre novas formas existentes de uso e oferta de produtos e serviços no meio virtual, pouco se utiliza esse recurso devido às limitações das instituições, o que tem feito com que os produtos e os serviços mais utilizados nos arquivos públicos sejam os que estão disponíveis no meio convencional, na maioria dos casos. Nos arquivos públicos, é fundamental a aplicação de métodos e técnicas 
arquivísticas para viabilizar o acesso e o uso da informação pública, e o papel do arquivista é muito importante no percurso desse processo.

\subsection{ARQUIVISTAS: PROFISSIONAIS DA INFORMAÇÃO COM HABILIDADES E COMPETÊNCIAS PARA DESENVOLVER PRODUTOS E SERVIÇOS DE INFORMAÇÃO}

Desde o nascimento, a Arquivologia vem se desenvolvendo através de suas práticas e teorias, mas foi na transição entre os Séculos XIX e XX que foi preciso adequar essa realidade aos avanços tecnológicos, fator que agrega potencialidade às práticas arquivísticas, especialmente em relação ao processo de disseminação das informações de maneira mais rápida e eficaz. A adoção de tecnologias de comunicação e informação facilita também $\mathrm{o}$ processo de tratamento, organização e armazenamento das informações arquivísticas. Essas mudanças são importantes, porque, além de atender às exigências do mercado, facilitam a comunicação e o acesso dos usuários às informações de que eles necessitam.

Lopes $(2009$, p. 58) desperta para a função do trabalho desses profissionais, ao afirmar que "[...] os arquivistas podem estabelecer essas relações entre as informações registradas e os conhecimentos gerais e específicos, dando ao seu trabalho mais do que uma visão fragmentada do saber [...]", pois passam a ser um produtor de conhecimento, pesquisador, especialista e responsável pela administração dos conteúdos informacionais que são produzidos e recebidos pelas organizações.

Nesse sentido, o arquivista pode ser considerado um produtor de conhecimentos, pois, quando organiza os arquivos, reconhece a fonte geradora e acumuladora de informação e passa a executar suas práticas para viabilizar o acesso às informações, como a construção do plano de classificação, o processo de avaliação documental, a descrição dos documentos, entre outras práticas voltadas para o usuário do serviço.

$\mathrm{Na}$ atual sociedade, compreendida como sociedade da informação, a informação se reveste de um valor importante para o cotidiano de uma instituição. Por isso, o profissional deve desenvolver habilidades e competências para trabalhar com ela de maneira eficaz (FERREIRA, 2003) e ajudar o usuário a ter acesso às informações. Sobre essa conjuntura, o desenvolvimento de produtos e serviços de informação pode viabilizar esse processo mais facilmente. Para isso, precisa estar atento às mudanças que ocorrem na sociedade. Com o desenvolvimento das tecnologias da informação e comunicação, está havendo mudanças na oferta de produtos e serviços, razão por que precisamos de profissionais cada vez mais habilitados e competentes para atender às demandas exigidas pelos usuários.

Um profissional da informação precisa ter uma boa formação acadêmica, atualizar-se e se capacitar para atender às necessidades do mercado de trabalho. Lopes (2009) alerta que o trabalho do arquivista pode ser mais profundo, se ele se propuser a organizar o conhecimento e/ou os conhecimentos produzidos e recebidos por uma organização ou pessoa, no sentido de suas especificidades e generalidades.

Sobre esse aspecto, Ponjuán Dante (2000, p.93) (tradução nossa) acrescenta:

[...] os profissionais da informação são aqueles que estão vinculados profissionalmente e intensivamente a qualquer etapa do ciclo de vida da informação e, portanto, devem ser capazes de operar eficiente e eficazmente em tudo que é relativo ao manuseio da informação em organizações de qualquer tipo ou em unidades especializadas de informação.

Logo, o arquivista precisa desenvolver competências e habilidades específicas para aplicá-las no arquivo (CARDOSO, VALENTIM; 2008). Dentre as habilidades e as competências do profissional de arquivo, destacamos o processo de geração, disseminação, recuperação, gerenciamento e disponibilização da informação. A construção e a aplicação de um plano de gestão documental são imprescindíveis nesse processo, para dar apoio aos gestores e ajudálos quando precisarem tomar decisões, assim como a criação de produtos e serviços de informação, não somente para o setor de arquivos, como também para todos os setores da instituição.

A informação deve ser disseminada e recuperada de forma rápida e eficiente, e a construção de produtos e serviços de informação é um meio facilitador desse processo. Portanto, é importante que o 
arquivista tenha habilidade para desenvolvêlos.

Sobre essa perspectiva, Menezes (2012) ressalta:

[...] é necessário que os profissionais da informação estimulem $\mathrm{o}$ processo de promoção dos produtos e serviços que são oferecidos nos arquivos, trazendo uma maior quantidade de usuários para a instituição, promovendo a sua fidelização, bem como, desmistificando a ideia de que o arquivo é destinado a uma minoria da população (MENEZES, 2012, p. 48).

Ressaltamos que o processo de promoção de produtos e serviços é um diferencial para a instituição, pois sua aplicação facilitará o acesso da informação pelos usuários e promoverá a instituição, seja pública ou privada. A seguir, apresentamos uma abordagem sobre os aspectos conceituais dos produtos e serviços de informação e sua aplicabilidade no contexto dos arquivos.

\section{PROCEDIMENTOS METODOLÓGICOS}

Este artigo é resultante de uma pesquisa realizada no primeiro semestre do ano de 2017, com o objetivo de compreender a realidade dos produtos e dos serviços arquivísticos oferecidos pelas Secretarias Estaduais da Paraíba.

No percurso metodológico desta pesquisa, transitamos, primeiramente, pela prática de uma revisão de literatura $r$ nos ancoramos na pesquisa bibliográfica para compreender os conceitos de arquivos, arquivos públicos, produtos e serviços de informação, e a atuação do arquivista como profissional da informação. A realização da pesquisa bibliográfica é fundamental para que se conheçam e analisem as principais contribuições teóricas sobre determinado tema ou assunto. É desenvolvida com base em material já elaborado, constituído, principalmente, de livros, artigos científicos, dissertações, teses etc. (GIL, 2008).

Em seguida, elaboramos como instrumento de pesquisa um questionário, que foi aplicado nas Secretarias do Estado da Paraíba, um instrumento de coleta de dados (MARCONI; LAKATOS, 2003), constituído de uma série de perguntas que devem ser respondidas e analisadas. Ao elaborar o questionário, selecionamos as questões e as direcionamos com a finalidade de conhecer o cenário dos produtos e dos serviços nos arquivos das Secretarias Estaduais da Paraíba. $\mathrm{O}$ questionário foi elaborado com doze questões abertas, para ser tabuladas quantitativamente. Elaboramos também um termo de consentimento livre e esclarecido, que foi assinado por todos os respondentes.

Depois de apresentar as instituições onde aplicaríamos o questionário, partimos para a pesquisa de campo, primeiramente das instituições públicas arquivísticas ligadas às Secretarias Governamentais do Estado da Paraíba. Quantificamos um total de 20 secretarias, muitas com arquivos agregados uns com os outros, devido ao baixo fluxo documental. Essa realidade de fusão de algumas secretarias, no âmbito dos arquivos, somada a algumas resistências a responderem aos questionários, possibilitou a aplicação em seis desses arquivos, todos situados no município de João Pessoa.

O questionário foi aplicado no período de 6 a 13 de abril de 2017 a dois funcionários de cada arquivo. Em duas instituições encontramos resistência para responder às perguntas, pois os funcionários tiveram receio de comprometer a instituição. Para assegurar o anonimato dos entrevistados e do que órgão ao qual estão vinculados, elaboramos um código para cada secretaria, associando letras em ordem alfabética. Logo, tivemos as instituições A, B, C, D, E e F, às quais foram distribuídos 12 questionários - dois para cada secretaria aplicados aos funcionários dos arquivos. Devido à dificuldade de acesso e à resistência dos funcionários, consideramos um recorte de seis Secretarias do Governo do Estado da Paraíba, que compuseram a amostragem.

No âmbito desta pesquisa, de caráter descritivo, quantitativo e qualitativo, buscamos compreender o panorama dos produtos e dos serviços informacionais arquivísticos nos arquivos estaduais das Secretarias do Governo da Paraíba. O foco ancora-se na descoberta da realidade dos produtos e dos serviços de informação nesses arquivos. As questões também buscaram esclarecer quais desses arquivos utilizam produtos e serviços informacionais e como esses recursos ajudam a disponibilizar as informações arquivísticas para o usuário. Depois de aplicar os questionários, seguimos com a análise dos dados coletados. 


\section{PRODUTOS E SERVIÇOS DE INFORMAÇÃO: COMPREENDENDO A REALIDADE DOS ARQUIVOS PÚBLICOS DAS SECRETARIAS DO GOVERNO DO ESTADO DA PARAÍBA LOCALIZADOS NA CIDADE DE JOÃO PESSOA (PB)}

A realidade nos arquivos públicos requer a aplicação da Lei 8.159 , de 08 de janeiro de 1991, denominada também de Lei dos Arquivos. Em seu art.1 $1^{\circ}$, assevera: "É dever do Poder Público e da gestão documental a proteção especial a documentos de arquivos, como instrumentos de apoio à administração, à cultura, ao desenvolvimento científico e como elementos e provas e informação". O Estado tem um papel importante na sociedade, pois serve de alicerce para a relação com o cidadão e garante $\mathrm{o}$ acesso às informações contidas nos acervos documentais. Assim, os arquivos públicos estaduais, nesse caso, têm como principais finalidades: disponibilizar aos órgãos as informações contidas nos acervos, reunir, coletar e examinar documentos históricos, facilitar sua consulta e torná-los úteis para fins administrativos e de pesquisa, visando preservar e difundir a memória cultural, principalmente quando tratamos da aplicação da Lei $n^{\circ} 12.527$, de 18 de novembro de 2011, lei de acesso à informação.

A Lei ${ }^{\circ} 12.527$, de 18 de novembro de 2011, que dispõe sobre o acesso à informação, trouxe a luz para os arquivos públicos brasileiros, como um instrumento de grande valor, que beneficiam diretamente a população. Ela entrou em vigor, através do decreto $\mathrm{n}^{\circ} 7.724$, de 16 de maio de 2012, abriu as portas para que qualquer pessoa possa conferir informações de interesse público que estejam armazenadas em instituições federais, estaduais e municipais e veio descortinar os movimentos dos documentos públicos movidos na gestão diária. Com um processo de transparência pública, ela deve abrir caminhos para que os diversos setores da sociedade promovam um controle social da informação, dando-lhe um caráter mais transparente e ativo no conceito de acesso à informação, reforçando, portanto, as atividades de gestão documental previstas na lei (Lei ${ }^{\circ} 8.159$, de 8 de janeiro de 1991), e fortaleçam o papel dos arquivos como mecanismos democratizantes e portadores de informação histórico-cultural (ARAÚJO; TANUS, 2013).

Nas visitas realizadas em alguns arquivos públicos estaduais localizados na cidade de João Pessoa (PB), percebemos a realidade em que se encontram e como estão sendo recebidos e tratados seus documentos. A falta de alguns produtos e serviços informacionais arquivísticos é evidenciada pelos profissionais das instituições, o que impossibilita a potencialização da importância dos arquivos nas instituições. A falta de conhecimento de novos recursos informacionais e de incentivos financeiros, os poucos recursos humanos e a falta de políticas públicas limitam o potencial dos arquivos das Secretarias Estaduais na Paraíba.

Entre os principais problemas percebidos nos arquivos estaduais, estão: o desconhecimento do papel do arquivista, a falta de interação entre os setores, a gestão documental que não é realizada a contento, a carência de profissionais qualificados, a precariedade de recursos materiais, o descaso com a conservação dos documentos e a falta de produtos e serviços informacionais.

Os arquivos das Secretarias Estaduais precisam de melhorias estruturais e materiais, pois muitos deles ainda não estão organizados de acordo com as práticas arquivísticas. De acordo com o que foi extraída dos questionários, tabulamos os dados, para possibilitar a análise do resultado alcançado. $\mathrm{O}$ objetivo não foi de pontuar a realidade específica da instituição, mas de compreender a realidade dos arquivos das Secretarias Estaduais de forma global.

Depois de aplicar o questionário, iniciamos o processo de organização e de análise dos dados. Primeiramente, analisamos a quantidade de funcionários que trabalham nos arquivos. Para isso, mapeamos um total de 48 funcionários nos seis arquivos, como demonstrado no Quadro 1.

Quadro 1: Quantidade de funcionários que trabalham nos arquivo das secretarias

\begin{tabular}{|c|c|}
\hline SECRETARIA & TOTAL DE FUNCIONÁRIOS \\
\hline A & 4 \\
\hline B & 10 \\
\hline C & 18 \\
\hline D & 3 \\
\hline
\end{tabular}




\begin{tabular}{|c|c|}
\hline \hline E & 3 \\
\hline F & 10 \\
\hline
\end{tabular}

Fonte: Dados da pesquisa

Com base nas observações feitas, constatamos que, de forma geral, as instituições investigadas se preocupam com o funcionamento desse setor, entre elas, a secretaria $\mathrm{C}$, com um total de 18 funcionários, diferentemente da realidade das secretarias D e E, cujo quadro funcional é de apenas três funcionários trabalhando em seus arquivos.

Quanto à existência de um profissional arquivista no quadro, encontramos uma realidade bem fragilizada (Quadro 2).

Quadro 2 - Panorama do quantitativo dos profissionais arquivistas que trabalham nos arquivos das Secretarias do Estado da Paraíba

\begin{tabular}{|c|c|}
\hline SECRETARIA & TOTAL DE FUNCIONÁRIOS \\
\hline A & 0 \\
\hline B & 2 \\
\hline C & 0 \\
\hline D & 1 \\
\hline E & 1 \\
\hline F & 0 \\
\hline
\end{tabular}

Fonte: Dados da pesquisa

De acordo com Lopes (2009 p.59), "[...] a existência de um arquivista como produtor de conhecimentos valoriza a profissão, pois o coloca no centro das decisões da organização, seja ela arquivística ou não". Por essa razão, é importante que, no corpo funcional dos arquivos, seja público ou privado, tenha um arquivista, inclusive para cumprir a Lei 8.159/91, Lei dos Arquivos (BRASIL, 1991) e promover o arquivo a um funcionamento de excelência, no que tange à recuperação, ao acesso e ao uso da informação, em tempo hábil, para auxiliar a tomada de decisão, e, sobretudo, aplicar a Lei $\mathrm{n}^{\circ} 12.527$, de 18 de novembro de 2011, que dispõe sobre o acesso à informação. $\mathrm{O}$ arquivista detém $\mathrm{o}$ conhecimento teórico e prático que viabilizam esse caminho.

O Quadro 2 demonstra que ainda há certa dificuldade de se compreender a importância da atuação desse profissional. Um ponto relevante foi o fato de, embora, nas instituições $\mathrm{D}$ e $\mathrm{E}$, o número de profissionais que trabalham no arquivo seja menor, três em cada um deles é profissional arquivista. Nem sempre, a quantidade de funcionários em um setor representa eficácia. Já a instituição B apresentou dez funcionários, um dos quais é arquivista.

Das secretarias que pesquisamos, apenas três têm arquivista. Na maioria delas existem profissionais de outras áreas desempenhando a função de técnico em arquivo. Ressaltamos que os arquivistas dessas instituições não são contratados para a função de arquivista, mas de assistentes administrativos. Essa realidade se deve ao fato de que o cargo de arquivista ainda não compõe o quadro de cargos e carreiras do Governo da Paraíba.

Em seguida, buscamos compreender a realidade documental dos acervos dessas secretarias e quais são os itens dos acervos mais recorrentes. Mariz (2011) afirma que a instituição que divulga seus fundos, os tipos de documentos, os assuntos e a data-limite possibilita ao usuário uma informação preliminar sobre o acervo, para que ele decida sobre quais são as vantagens e as desvantagens de sua ida ao arquivo.

Quadro 3 - Panorama dos acervos das Secretarias do Estado da Paraíba

\begin{tabular}{|c|c|}
\hline SECRETARIA & TOTAL DE FUNCIONÁRIOS \\
\hline A & Leis, decretos e atos administrativos \\
\hline B & Dossiês de usuários externos \\
\hline C & Processos administrativos \\
\hline D & Prestação de contas \\
\hline E & Convênios, prestações de contas, frequência \\
\hline
\end{tabular}




\begin{tabular}{|c|c|}
\hline \hline F & Prestação de contas \\
\hline
\end{tabular}

Fonte: Dados da pesquisa

Considerando as respostas dos funcionários, constatamos, de acordo com o quadro 3, que há uma diversidade de documentos que cada órgão abriga. Essa heterogeneidade documental advém do fato de se tratar de órgãos com diferentes funções no Estado, divididos em setores administrativo, jurídico, financeiro e de pessoal.

O Quadro 3 aponta que, das seis secretarias analisadas, três não têm ou não conhecem produtos e serviços arquivísticos. Isso confirma a afirmação da autora a respeito da falta de definições sobre o referido tema. As outras três instituições que disseram que têm produtos e serviços arquivísticos os disponibilizam através de um site do Governo do Estado e pelo uso de instrumentos tradicionais de pesquisa.

Em seguida, buscamos compreender se nos arquivos pesquisados existem produtos e serviços arquivísticos. O Quadro 4 traz esse panorama:

Quadro 4 - Realidade dos produtos e serviços arquivísticas dos arquivos das Secretarias Estaduais da Paraíba na perspectiva dos funcionários

\begin{tabular}{|c|c|c|}
\hline SECRETARIAS & TEM & PRODUTOS E SERVIÇOS \\
\hline A & NÃO RESPONDEU & Não soube definir produtos e serviços. \\
\hline B & NÃO RESPONDEU & Não soube definir produtos e serviços. \\
\hline C & SIM & Recuperação da informação (via WEB) \\
\hline D & SIM & Recuperação da Informação (via WEB) \\
\hline E & NÃO & \\
\hline F & SIM & Recuperação da informação- usuário interno \\
\hline
\end{tabular}

Fonte: Dados da pesquisa

No contexto geral dos arquivos, observamos que há certa dificuldade de se compreender o que são produtos e serviços informacionais, inclusive nos arquivos em cujo quadro funcional há arquivistas. Sobre essa perspectiva, Silva (2013) enuncia que ainda são confusos os entornos conceituais dos produtos e dos serviços de informação e que, na literatura de referência da Ciência da Informação e de outras áreas afins, encontramos muitas características e poucas definições de produtos e serviços arquivísticos. Nessa conjuntura, apenas $50 \%$ das secretarias que fizeram parte de nossa amostra conhecem os produtos e os serviços informacionais e os aplicam em sua realidade. Todas citaram a tecnologia como uma aliada para a oferta de produtos e serviços.

Seguindo nossa análise, direcionamos especificamente o questionamento para a inserção de seus produtos e serviços no ciberespaço ou no ambiente tradicional. (Quadro 5)

Quadro 5 - Realidade dos produtos e serviços informacionais no ciberespaço ou no ambiente tradicional

\begin{tabular}{|c|c|c|}
\hline SECRETARIA & $\begin{array}{c}\text { PRODUTOS E SERVIÇOS } \\
\text { INFORMACIONAIS NO } \\
\text { CIBERESPACÇO }\end{array}$ & $\begin{array}{c}\text { PRODUTOS E SERVIÇOS } \\
\text { INFORMACIONAIS TRADICIONAIS }\end{array}$ \\
\hline A & NÃO & SIM \\
\hline B & NÃO & NÃO \\
\hline C & SIM & SIM \\
\hline D & NÃO & NÃO \\
\hline E & NÃO & NÃO \\
\hline F & NÃO & NÃO \\
\hline
\end{tabular}

Fonte: Dados da pesquisa

De acordo com o levantamento realizado, constatamos que só $28 \%$ das secretarias dispõem de produto informacional online e tradicional, e $72 \%$ não dispõem de nenhum 
tipo. No percurso dessa análise, vimos que há certa fragilidade das instituições em seus arquivos quanto ao uso de produtos e serviços informacionais tradicionais ou virtuais. Essa realidade ocorre em virtude do desconhecimento de sua existência e da falta de interesse em utilizar, elaborar ou adquirir esses instrumentos de pesquisa, os produtos e os serviços informacionais, com vistas a facilitar o processo de trabalho, a tomada de decisão, $o$ alcance mais rápido das informações e sua disseminação.

Devido ao número reduzido de instituições que utilizam as duas realidades de produtos e serviços, em apenas uma o produto informacional usado para buscar essas informações online é restrito para o usuário interno, pois se trata de um programa que serve para localizar o documento na instituição. No produto informacional tradicional que eles utilizam estão a tabela de temporalidade, o índice, o plano de classificação e o inventario. Já o serviço informacional disponível para o usuário externo é o site do Governo do Estado, em que se pode ter acesso através de uma numeração para acompanhar determinado processo.

Buscamos entender como se dá o acesso às informações por parte dos usuários internos e externos. Para isso, recorremos à visão do corpo funcional do arquivo sobre a abertura ou a limitação desse acesso e percebemos há uma preocupação mais focada na restrição ou nas dificuldades do que no acesso às informações. Isso corrobora o descaso com a existência dos produtos e dos serviços informacionais nesses arquivos.

Quadro 6 - Acesso ou restrição às informações pelos usuários internos e externos

\begin{tabular}{|c|c|c|c|}
\hline SECRETARIA & DIFICULDADES & RESTRIÇÃO & QUAIS DIFICULDADES \\
\hline A & Não & SIM & -- \\
\hline B & Sim & SIM & Organização do Acervo \\
\hline C & Não & NÃO & -- \\
\hline D & Sim & NÃO & Não soube definir quais. \\
\hline E & Sim & NÃO & Falta de comunicação \\
\hline F & Não & NÃO & -- \\
\hline
\end{tabular}

Fonte: Dados da pesquisa

O Quadro 6, abaixo, ilustra a dificuldade dos usuários internos e externos de ter acesso às informações e a existência de barreiras constatadas pelas dificuldades de acesso a essas informações. Em 50\% das instituições, há dificuldades quanto ao acesso às informações, devido à falta de organização do acervo ou de comunicação entres os setores. Já as outras 50\% não têm dificuldade de acesso, mas, para disponibilizar as informações, é preciso que o usuário esteja na ativa e solicite o processo no setor de protocolo da instituição.

Silva e Costa (2014) entendem que o uso da internet nos arquivos pode desenvolver serviços e produtos, além dos elaborados e desenvolvidos usualmente, e proporcionar inúmeros benefícios em relação ao tratamento da informação, desde o acesso digital dos documentos até um mecanismo de busca, com o fim de facilitar a recuperação da informação.
Outra análise importante realizada foi a respeito da restrição dos usuários internos e externos para obter as informações. Em $28 \%$ das instituições é restrito o acesso devido ao fato de os documentos contidos no arquivo serem de interesse pessoal ou apresentarem grau de sigilo. Nos restantes $72 \%$, o acesso está disponível para os que necessitarem. Porém, antes passam por uma análise no arquivo ou através do site do Governo do Estado, onde o usuário externo tem acesso à tramitação de determinado documento.

Para entender como os profissionais que trabalham nesses arquivos enxergam os produtos e os serviços de informação, perguntamos-lhes qual a importância da implementação de produtos e serviços de informação para seus respectivos setores, utilizando o ciberespaço, e se eles consideram necessário. As respostas estão compiladas no Quadro 7. 
Relatos de Pesquisa

Quadro 7 - Importância e implementação de produtos e serviços informacionais no ciberespaço

\begin{tabular}{|c|c|c|}
\hline SECRETARIA & IMPORTANTE & IMPLANTAÇÃO \\
\hline A & Sim & Sim \\
\hline B & Não responderam. & Sim \\
\hline C & Sim & Não responderam. \\
\hline D & Não & Não \\
\hline E & Sim & Sim \\
\hline F & Sim & Não \\
\hline
\end{tabular}

Fonte: Dados da pesquisa

Segundo as respostas obtidas, $66,66 \%$ dos pesquisados admitem que é importante oferecer produtos e serviços informacionais no ciberespaço, com o fim de facilitar o acesso e a comunicação de forma mais rápida e eficaz. Somente $16,67 \%$ não quiseram responder a respeito de sua visão sobre a importância dos produtos e dos serviços de informação para o arquivo, e 16,67\% disseram que não acreditam na importância dos produtos e dos serviços de informação no ciberespaço, ou seja, que preferem manter sua realidade.

De acordo com a Lei $\mathrm{n}^{\circ} 12.527$, de 18 de novembro de 2011, Art. $8^{\circ}$, é dever dos órgãos e das entidades públicas promoverem, independentemente de requerimentos, a divulgação, em local de fácil acesso, no âmbito de suas competências, de informações de interesse coletivo ou geral por eles produzidas ou custodiadas (BRASIL, 2011).

Continuando a análise do quadro 7, 50\% das instituições demonstram ter abertura para propostas de implementação de produtos e serviços, mesmo sabendo que os gestores das secretarias não têm interesse em investir nos arquivos. Em oposição, 33,33\% das instituições não se interessam em analisar propostas de inovações tecnológicas nos arquivos, argumentando que não teria utilidade para sua entidade. Apenas 16,67 optaram por não responder a essa pergunta, mas o curioso é que, de acordo com os dados, a instituição que não quis revelar sua opinião sobre a implementação de produtos e serviços no ciberespaço, julga importante a aplicabilidade dos produtos e dos serviços informacionais.

No contexto desta pesquisa, buscamos também investigar o cenário das limitações no contexto desses produtos e serviços informacionais, especialmente no âmbito tecnológico, porque compreendemos que barreiras existem, mas, para ultrapassá-las, precisamos conhecê-las. O quadro 8 revela essa realidade nos arquivos das Secretarias Estaduais da Paraíba.

Quadro 8 - Barreiras na implantação de produtos/serviços no meio digital

\begin{tabular}{|c|c|}
\hline SECRETARIA & BARREIRAS \\
\hline A & Falta de verbas \\
\hline B & Estrutura (equipamentos) e profissionais \\
\hline C & Profissionais qualificados e falta de interesse do Estado \\
\hline D & Burocracia e falta de conhecimento \\
\hline E & Arquivo não é valorizado e Estado não tem interesse \\
\hline F & Falta de verbas e de interesse do Estado \\
\hline
\end{tabular}

Fonte: Dados da pesquisa

A disponibilização de acervos arquivísticos na internet apresenta muitas vantagens, entre elas: facilitar o acesso, atingir um público maior, ampliar o atendimento aos pesquisadores, permitir pesquisas, aumentar a divulgação, dentre outras (MARIZ, 2011, p.109).
$\mathrm{O}$ Quadro 8 mostra que as barreiras existentes para a implantação de produtos e serviços informacionais no arquivo dessas instituições estão relacionadas com a falta de verbas, de estrutura, profissionais não qualificados, falta de interesse do Estado e, principalmente, falta de conhecimento sobre o tema, o que demonstra certa fragilidade em 
relação ao conhecimento e ao reconhecimento da importância dos produtos e dos serviços informacionais no contexto dos arquivos.

No contexto analisado, percebemos que é preciso implantar produtos e serviços informacionais, contratar profissionais arquivistas e incentivar o programa de gestão de documentos. O primeiro elemento abordado refere-se à implantação de produtos e serviços informacionais, porque a maioria não os tem devido à falta de compreensão sobre a finalidade e a função dos produtos dos serviços para a unidade de informação. A fragilidade atinge a gestão de documentos, em detrimento da falta de instrumentos importantes, como o plano de classificação, tabela de temporalidade, inclusive dos instrumentos de pesquisa, entre outros. Outro ponto importante foi relativo à necessidade de contratar profissionais arquivistas, cuja profissão ainda não é bem valorizada nem reconhecida na realidade dos arquivos das secretarias analisadas. Por fim, O quarto item é a respeito do incentivo ao programa de gestão de documentos. A pesquisa mostrou que não há interesse em aplicá-lo e desenvolvê-lo e uma barreira para a implantação de novos recursos tecnológicos, que facilitaria o acesso informacional nas secretarias.

\section{CONSIDERAÇÕES FINAIS}

De acordo com o que foi visto nos arquivos, atualmente, não existe ambiente adequado para a criação e a oferta de produtos e serviços que consigam atingir e fomentar uma demanda de necessidades de informação dos usuários, sejam internos ou externos, embora a implantação da oferta de produtos e de serviços informacionais arquivísticos nos arquivos das Secretarias do Estado da Paraíba seja importante, especialmente para seus usuários, pois facilitaria o acesso às informações no ambiente tradicional e no virtual.
A pesquisa revelou algumas fragilidades, tanto no que diz respeito à compreensão dos produtos e dos serviços informacionais quanto à aplicabilidade e ao seu uso. Esse cenário ocorre por meio de uma série de fatores, que vão desde a falta de recursos, até a resistência de implementação desses produtos, especialmente no campo digital.

Sabemos que o arquivo é um elemento importante para a instituição, pois é nele em que se encontram documentos produzidos e recebidos para o exercício de suas atividades, que servem como prova e cumprem sua função social nos arquivos permanentes. Independentemente da fase que o documento apresenta, o foco deve ser a garantia do acesso à informação e a salvaguarda dos documentos que apresentam graus de sigilo. Além disso, os arquivos são instrumentos de gestão, indispensáveis à eficiência, à transparência e à eficácia nas áreas administrativas para o desenvolvimento e o interesse social e político de uma sociedade.

O estudo mostrou, ainda, que a maioria das instituições avaliadas não tem produtos $\mathrm{e}$ serviços informacionais, profissionais qualificados para a função, gestão documental e aceitação para a execução de produtos e serviços. Isso se justifica porque o grande entrave é a falta de interesse, ora dos responsáveis pelos arquivos e seus respectivos funcionários, ora dos gestores, haja vista que dependia de do investimento de recursos para modificar essa realidade.

Assim, concluímos que é preciso haver mais divulgação e oferta de produtos e serviços informacionais nas instituições públicas, mais valorização dos profissionais capacitados para exercer suas atividades nos arquivos, incentivos financeiros e uma abertura dos gestores para propostas de inovações relacionadas ao acesso à informação nas instituições.

\title{
PRODUCTS AND INFORMATION SERVICES IN PUBLIC ARCHIVES: THE ARCHIVES' CASE OF PARAÍBA STATE SECRETARIATS
}

\begin{abstract}
:
It addresses the availability of products and services offer in public archives of Paraíba state. It is a descriptive research with a quantitative and qualitative approach. The questionnaire was used as a tool for data collection, applied to a sample of six secretariats surveyed. With the purpose of knowing the offer of
\end{abstract}


products and information services in the public archives of the State of Paraíba in the traditional and virtual environment. It presents the conceptual, typological and definitions aspects of archival information products and services. It shows the role of the archivist as an information professional, as well as the habilities and skills to promote the dissemination of products and services in organizations. The research reveals professionals limitations in public archives of Paraíba, making informational potential impossible. It is concluded that there is a low supply of products and services in the archives of the secretariats, mainly in cyberspace due to the lack of availability of human and financial resources to implement them.

Keywords: Public Archives - Paraíba State. Public Arcives - Products and Services.

\section{REFERÊNCIAS}

ALBUQUERQUE, P. R. de. Reflexões sobre a divulgação de produtos e serviços em arquivos e o papel do arquivista. João Pessoa: UFPB, 2015.

ARAÚJO, C. A. A. Condições teóricas para a integração epistemológica da Arquivologia, da Biblioteconomia e da Museologia na Ciência da Informação. In CID: R. Ci. Inf. e Doc., Ribeirão Preto, v. 2, n. 2, p. 19-41, jul./dez. 2011. Disponível em: $<$ http://revistas.ffclrp.usp.br/incid/article/v iew/55/pdf $>$. Acesso em: 20 jan. 2014.

ARAÚJO, C. A. A.; TANUS, G. F. de S. C. $\mathrm{O}$ ensino da Arquivologia no Brasil: fases e influências. Encontros Bibli: revista eletrônica de Biblioteconomia e Ciência da Informação, v. 18, n. 37, p. 83-102, mai./ago., 2013.

ASSIS, Wilson Martins de. Metodologia para construção de produtos de informação nas organizações. 2006. Dissertação (Mestrado em Ciência da Informação) - Escola de Ciência da Informação, Universidade Federal de Minas Gerais, Belo Horizonte, 2006.

BELLOTTO, Heloísa Liberalli. Arquivos permanentes: tratamento documental. 4. ed. Rio de Janeiro: Editora FGV, 2006.

BEHR, Ariel; MORO, Eliane Lourdes da Silva; ESTABEL, Lizandra Brasil. Uma proposta de atendimento às necessidades de informação dos usuários da biblioteca escolar por meio do benchmarking e do sensemaking. Informação \& Informação, Londrina, v. 15, n. 1, p. 37-54, jan./jun. 2010. Disponível em: $<$ http://www.uel.br/revistas/uel/index.php/inf ormacao/article/view/4350/5877> . Acesso em: 11 mai. 2017.

BORGES, Mônica Erichen Nassif. O essencial para a gestão de serviços e produtos de informação. Revista Digital de Biblioteconomia e Ciência da Informação, Campinas, v. 5, n. 1, p. 115-128, jul./dez. 2007.

BRAZIL. Lei ${ }^{\circ} 6.546$ de 4 julho de 1978.

Dispõe sobre a regulamentação das profissões de arquivista e técnico em arquivo e dá outras providências. Brasília: Casa Civil, 1978.

BRASIL. Decreto lei n. 8.159 de 08 de janeiro de 1991. Dispõe sobre a política nacional de arquivos públicos e privados $\mathrm{e}$ dá outras providências. Diário Oficial [da] República Federativa do Brasil, Brasília, D.F., 8 jan. 1991.

BRASIL. Lei $\mathrm{n}^{\circ} 12.527$ de 18 de novembro de 2011. Regulamenta o direito constitucional de acesso às informações públicas. Diário Oficial [da] República Federativa do Brasil, Brasília, D.F., 18 nov. 2011.

CARDOSO, Débora Regina; VALENTIM, Maria Lígia Pomim. Perfil do profissional arquivista para atuar na gestão documental em ambientes empresariais. 2008. Disponível em: < http://www.enearq2008.ufba.br/wpcontent/uploads/2008/09/13debora_regina_cardoso.pdf > Acesso em: 13 jun. 2017. 
CASTELLS, Manuel. A sociedade em rede. 7. ed. São Paulo: Editora Paz e Terra, 2003, v. 1.

CASTRO, Maria de Fatima Coelho; SUAIDEN, José Emir. Fatores críticos de sucesso na oferta de produtos e serviços de informação na web. Pesquisa Brasileira em Ciência da Informação e Biblioteconomia, João Pessoa, v. 10, n.1, p. 001-028, 2015.

CHAGAS, P. D.; PEREIRA, I. M. L. Arquivo e memória: uma análise dos conceitos de arquivo segundo Michel Foucault e Roberto Gonzalez Echevarría. Fólio - Revista de Letras, Vitória da Conquista, v. 3, n. 2, p. 319-331, 2011.

FERREIRA, Danielle Thiago. Profissional da Informação: perfil de habilidades demandadas pelo mercado de trabalho. Ci. Inf., Brasília, v.32, n.1, p.42-49, jan./abr. 2003.

GONÇALVES, Marcos Rogério; GOUVEIA, Sônia Mara; PETINARI, Valdinéa Sônia. A informação como produto de alto valor no mundo dos negócios. CRB-8 Digital, São Paulo, v. 1, n. 1, p. 43-54, jul. 2008.

GIL, Antonio Carlos. Como elaborar projetos de pesquisa. 4. ed. São Paulo: Atlas, 2008.

GIROTO, Luan; CALDAS, Rosângela. Produtos e serviços em websites de arquivos públicos estaduais como contributo para a cultura informacional. IV SECIN, Londrina, agosto de 2016.

HORTINHA, Joaquim. E-marketing. Lisboa: Edições SÍLABO, 2001.

KOTLER, P; KELLER, K. L. Administração de Marketing. 12. ed. São Paulo: Pearson Prentice Hall, 2006.

LOPES, Luís Carlos. A nova arquivística na modernização administrativa. 2. Ed.

Brasília: Projecto Editorial, 2009.

MARCONI, M. de A.; LAKATOS, E. M. Fundamentos de metodologia científica. 5. ed. São Paulo: Atlas, 2003.
MARIZ; Anna Carla Almeida; Arquivos públicos brasileiros: análise da evolução da transferência da informação arquivística na Internet. Enc. Bibli: R. Bibliotecon. Ci.Inf., Florianópolis, n. esp., $1^{\circ}$ sem. 2011.

MARTELETO, Regina Maria. Cultura, Educação e Campo Social: discursos e práticas de informação. 1992. 390 f. Tese (Doutorado em Comunicação) - Escola de Comunicação, Universidade Federal do Rio de Janeiro, Rio de Janeiro, 1992.

MENEZES, Priscila Lopes. O processo de difusão desenvolvido pelos arquivos públicos estaduais da Região Sul do Brasil. Ponto de Acesso, Salvador, v.6, n.3, p. 47-71, 2012.

PAES, Marilane Leite. Arquivo: teoria e prática. 3. ed. Rio de Janeiro: FGV, 2006. PONJUÁN DANTE, G. Perfil del professional de informacion del nuevo milênio. In: VALENTIM, M. L. P. (Org.). $\mathbf{O}$ profissional da informação: formação, perfil e atuação. São Paulo: Pólis, 2000. p.91-105.

(Coleção Palavra-Chave, 11).

RIBEIRO, Fernanda. O perfil profissional do arquivista na sociedade da informação. In: JORNADAS LUSO-CABOVERDIANAS EM CIÊNCIAS SOCIAIS-PORTUGAL E CABO VERDE, 4., 2004, Porto. Anais... Porto, 2004. Disponível em: <http://ler.letras.up.pt/uploads/ficheiros/artigo 8871.PDF> Acesso em: 23 de abril de 2017.

ROZADOS, Helen Beatriz Frota.

Indicadores como ferramenta para gestão de serviços de informação tecnológica. 2004. 239f. Tese (Doutorado em Ciência da Informação) - Faculdade de Biblioteconomia e Comunicação, Universidade Federal do Rio Grande do Sul, Porto Alegre, 2004.

SILVA, Wystercley Marins da. Arquivos de interesse público e social: a atuação do Conselho Nacional de Arquivos, 2011, 146 p. Dissertação (Mestrado em Ciência da Informação) Programa de Pós-graduação em Ciência da Informação, Universidade Federal Fluminense, Niterói, 2011.

SILVA, Ismaelly Batista dos Santos. Consultoria arquivística aplicada à gestão de produtos e serviços de informação no 
NDPI/UFPB. In: CONFERÊNCIA SOBRE TECNOLOGIA, CULTURA E MEMORIA: ESTRATÉGIAS PARA PRESERVAÇÃO E ACESSO À INFORMAÇÃO (CTCM), 2013, Recife. Anais... Recife: UFPE, 2013.

Disponível em:

<http://www.liber.ufpe.br/ctcm2013/anais/file s/7b.CAAGPSI_NDPI-UFPB.pdf $>$. Acesso em: 16 mai. 2017.
SILVA, Patrícia; COSTA, João Henrique Lucena da. Produtos e serviços oferecidos pelo Arquivo do Centro de Ciências Humanas, Letras e Artes da Universidade Federal da Paraíba. Archeion online, João Pessoa, v.2, n.1, p.90-105, jan/ jun.2014. 